Published in final edited form as:

Clin Endocrinol (Oxf). 2020 February ; 92(2): 138-144. doi:10.1111/cen.14132.

\title{
Compromised endothelial function in transgender men taking testosterone
}

\author{
Barbara I. Gulanski ${ }^{3}$, Clare A. Flannery ${ }^{2,3}$, Patricia R. Peter ${ }^{3}$, Cheryl A. Leone ${ }^{1}$, Nina S. \\ Stachenfeld ${ }^{1,2}$ \\ ${ }^{1}$ The John B. Pierce Laboratory, New Haven, CT, 06519, \\ ${ }^{2}$ Department of Obstetrics, Gynecology and Reproductive Sciences, New Haven, CT, 06520 \\ ${ }^{3}$ Department of Medicine, Section of Endocrinology, Yale School of Medicine, New Haven, CT, \\ 06520
}

\section{SUMMARY}

Context.-Transgender men (TGM) are persons assigned female gender at birth with a male gender identity and are routinely treated with testosterone. Androgen excess is associated with endothelial dysfunction among cisgender females (CGF) and is an early sign of atherosclerosis and hypertension.

Objective.-To determine the effect of testosterone treatment on endothelial function in TGM.

Setting.-The John B. Pierce Laboratory and Yale School of Medicine

Subjects.-Eleven TGM (age $27 \pm 5$ y; BMI $24.4 \pm 3.7 \mathrm{~kg} / \mathrm{m}^{2}$ ) receiving testosterone (T) and 20 CGF (28 \pm 5 y; BMI $26.0 \pm 5.1 \mathrm{~kg} / \mathrm{m}^{2}$ ) during the early follicular phase of their menstrual cycle.

Design and Outcome Measures.-We evaluated brachial vasodilatory responses following stimuli designed to elicit shear stress using 3-min occlusion to determine endothelial function (flow mediated vasodilation, FMD).

Results.-Total T was greater in the TGM compared to CGF ( $484.6 \pm 122.5$ vs. $1.5 \pm 0.7 \mathrm{ng} / \mathrm{dL})$, as was free $\mathrm{T}(83.9 \pm 32.4$ vs. $1.9 \pm 0.8 \mathrm{pg} / \mathrm{dL})$. FMD was markedly lower in the TGM (4.5 $\pm 2.7 \%)$ compared to the $\mathrm{CGF}(8.1 \pm 2.9 \%, \mathrm{P}=0.002)$ indicating significantly diminished endothelial function in TGM.

Corresponding author: Nina S. Stachenfeld, John B. Pierce Laboratory, 290 Congress Ave., New Haven, CT 06510, Phone: 203.562.9901 x219, Fax: 203.624.4950, nina.stachenfeld@yale.edu.

Author Contributions:

- C.A.L. ran the flow mediated vasodilation experiments, assisted with all human data collection, conducted the hormone assays and analyzed the hormone data.

- $\quad$ B.I.G. \& P.R.P screened and supervised the subjects on medication.

- $\quad$ N.S.S. supervised the project, assisted in data collection, aided in interpreting results.

- $\quad$ N.S.S., B.I.G, \& C.A.F. devised the project and collaborated in writing the manuscript.

Disclosure statement. Authors have nothing to disclose.

DATA AVAILABILITY STATEMENT

The data that support the findings of this study are available from the corresponding author upon reasonable request. 
Conclusions.-We have shown for the first time that in TGM the androgen-dominant hormonal milieu was associated with impaired endothelial function. Endothelial dysfunction precedes clinically detectable atherosclerotic plaque in the coronary arteries, so is an important marker for clinical cardiovascular risk. Therefore, attention to cardiovascular risk factors should be integral to the care of transgender men.

\section{Keywords}

androgens; flow mediated vasodilation; cardiovascular risk; cross-sex hormone therapy

\section{INTRODUCTION}

Approximately $0.6 \%$ or 1.4 million people in the U.S. identify as transgender ${ }^{1}$, or having a current gender identity that differs from the sex assigned at birth. Cisgender individuals have a gender identity the same as the sex assigned at birth, thus cisgender women are persons assigned female at birth with a female gender identity. Transgender men are persons assigned female at birth with a male gender identity. It is common for TGM to undergo gender affirming hormone therapy (HT), including both reducing ovarian hormones and increasing testosterone. Gender affirming hormone therapy for TGM can be include continuous, lifelong androgen exposure.

While the impact of chronic androgen exposure in TGM has not been well studied, testosterone is associated with increased cardiovascular risk in women ${ }^{2-4}$. In general, the engagement of androgen and the androgen receptor (AR) results in impaired agonisttriggered endothelial nitric oxide (NO) release in women ${ }^{5,6}$ and testosterone exposure is characterized by endothelial dysfunction ${ }^{7,8}$. Excess free plasma testosterone in women is also a predictor of sympathetic nervous system-mediated increases in blood pressure and renal sympathetic activation. For example, in women with androgen excess-polycystic ovary syndrome (AE-PCOS), peripheral vascular sympathetic nervous system activity is increased independent of other comorbidities associated with $\mathrm{PCOS}^{9}$. The complete etiology of AEPCOS remains unknown, but is a complex condition characterized by disordered ovarian estradiol, disrupted ovarian progesterone and excess ovarian androgen secretion, in addition to compensatory hyperinsulinemia and menstrual irregularities ${ }^{10}$. Women with AE-PCOS are a corollary to TGM due to their chronic, lifelong androgen exposure, and young women with AE-PCOS have a number of cardiovascular comorbidities, including mild hypertension, enhanced sympathetic activity and endothelial dysfunction ${ }^{9,11}$. It is therefore logical that the HT for TGM may increase their cardiovascular risk, and these risks may be compounded by other medical or surgical interventions. Even in young TGM cohorts, testosterone therapy consistently increases systolic blood pressure ${ }^{12-16}$, triglycerides ${ }^{15,16}$ LDL-cholesterol and decreases HDL-cholesterol ${ }^{14,} 17$.

Testosterone exposure can begin in many TGM at an age when the overall risk for cardiovascular events is still low. It is therefore important to evaluate biomarkers and risk factors that can predict cardiovascular dysfunction and disease later in life. Endothelial dysfunction precedes clinically detectable atherosclerotic plaques in the coronary arteries, so is an important marker for cardiovascular risk. In this study, we evaluated the impact of 
physiological doses of testosterone as part of HT on endothelial dysfunction in TGM. We hypothesized that endothelial function would be impaired in TGM taking HT compared to CGF of similar age and health parameters.

\section{MATERIALS AND METHODS}

\section{Subjects.}

Eleven TGM ( $27 \pm 4,20-31$ yrs $)$ and 20 healthy cisgender, premenopausal women ( $28 \pm 5$, 18-34 yrs) voluntarily provided written informed consent to participate. All CGF had regular menstrual cycles (28-32 days), and no subjects were using hormonal contraceptives or taking hormones of any kind other than the prescribed testosterone in the TGM.

Participants were non-smokers, with no reported history of cardiovascular, metabolic, or gynecological disease. Subjects were sedentary or recreationally active. The study conformed to guidelines contained in the Declaration of Helsinki and was approved by the Human Investigation Committee of the Yale School of Medicine.

\section{Experimental design.}

We evaluated brachial vasodilatory responses with FMD one time in each subject. Transgender men were taking physiological doses of exogenous testosterone (via injection) for at least three months as prescribed by their endocrine provider as part of their clinically indicated HT. The testosterone dose varied among the TGM depending on their treatment goals $^{18}$. All TGM were prescribed weekly doses of testosterone cypionate ranging from 40 $80 \mathrm{mg}$ by subcutaneous injection. The TGM group was instructed to have testosterone levels measured at peak and trough to ensure that testosterone levels remained within the physiologic male range throughout the dosing interval. Given that testosterone injections were administered on a weekly basis, with one subject prescribed on a twice weekly basis, there was minimal peak and trough effect on testosterone levels during the dosing interval. Circulating testosterone levels were within the normal male physiologic range for TGM, and female physiological ranges for CGF (Table 1). Cisgender females were tested within days 1-7 of the follicular phase of their menstrual cycle.

\section{Experimental protocols.}

Subjects had abstained from food, alcohol, caffeine, and strenuous exercise for $12 \mathrm{~h}$ prior to FMD testing. Testing was performed in the morning in a dimly lit environmental chamber $\left(\mathrm{Ta}=26^{\circ} \mathrm{C}\right)$. Before FMD testing, subjects rested supine for at least 15 minutes. In our CGF, following the FMD studies, after at least 30 min of seated rest, a blood sample was drawn to measure serum concentrations free and total testosterone $\left(\left[\mathrm{T}_{[\text {free }]} \mathrm{S},{ }_{[} \mathrm{T}_{[\text {Total }]} \mathrm{S}\right)\right.$, plasma cholesterol [total cholesterol (TC), high (HDL) and low density (LDL) lipoproteins] and triglycerides. Because hormone and lipid panels had been determined by their personal physicians, we did not draw blood on the TGM on the day of the FMD testing to avoid being overly invasive. Testosterone levels were tested TGM within two months of their last blood tests for the reported measurements.

Flow-mediated vasodilation.-Subjects lay supine with their right arm extended. Continuous recordings of longitudinal brachial artery images and blood flow velocity were 
obtained simultaneously using the Sonoscope $\mathrm{S} 2$ ultrasound imaging system with a 6.0-MHz linear array probe (International Diagnostic Devices, Las Vegas, USA). A probe holder secured the ultrasound transducer in place at a location on the brachial artery distal to the antecubital fossa to ensure that the same vessel segment was measured throughout each test date. The ultrasound display was captured continuously using a VGA to S-Video converter and recorded in AVI format on an external computer (StarTech, London, Canada). In each protocol, brachial artery measures were recorded at baseline for 3 minutes. Forearm ischemia was then induced by rapidly inflating a blood pressure cuff to supra-systolic pressure (i.e. $\geq 160-180 \mathrm{mmHg}$ ) for five minutes. Brachial artery measures were obtained continuously for 3 minutes following cuff deflation. Using similar methodology for an enhanced shear stress stimulus, it has been shown that FMD is highly repeatable within subjects across trials and across days ${ }^{19-21}$.

\section{Blood analysis}

For cisgender women.-An aliquot was transferred into a tube without anticoagulant for the determination of lipids and $\mathrm{T}$ (free and total). An aliquot $(1 \mathrm{ml})$ was removed for immediate assessment of hematocrit (Hct) and hemoglobin ([Hb]) in triplicate by microhematocrit and cyanomethemoglobin respectively. Serum concentrations of T (free and total) were measured using enzyme-linked immunosorbent assay (ELISA) methods. Intraand inter-assay coefficients of variation for $\left[\mathrm{T}_{\text {Total }}\right] \mathrm{S}$ were $5.7 \%$ and $5.7 \%$ (Alpco, Salem, $\mathrm{NH}$ ), and $\left[\mathrm{T}_{\text {free }}\right] \mathrm{S}$ were $3.9 \%$ and $4.0 \%$ (Alpco). Total cholesterol, HDL, LDL were measured with a cholesterol assay kit (ab65390) and triglycerides were measured with a triglyceride assay kit (ab65336) using an AW Alera analyzer (Alfa Wasserman Co, West Caldwell, NJ). Hemoglobin A1c $\left(\mathrm{HbA}_{1 \mathrm{C}}\right)$ was collected in EDTA and assayed using immunoturbidimetry.

For transgender men.-Total-cholesterol, HDL-cholesterol and triglycerides were collected in heparin and were measured by spectrophotometry at Quest Diagnostics. LDLcholesterol was calculated using the Martin-Hopkins calculation ${ }^{22}$. Hemoglobin A1c was collected in EDTA and assayed using immunoturbidimetry at Quest Diagnostics. The normal range $\mathrm{HbA}_{1 \mathrm{C}}$ is $<5.7 \%$. Prediabetes is defined as an $\mathrm{A} 1 \mathrm{c} 5.7-6.4 \%$, and diabetes is an $\mathrm{A} 1 \mathrm{c}$ $6.5 \%$ or greater.

\section{Data analysis}

Flow mediated vasodilation.-Machine-learning software (Brachial Analyzer for Research, Medical Imaging Applications, Coralville, USA) was used to analyze ultrasound screen-capture files. Edge-detection software was used to measure vessel diameter throughout each protocol and reviewed manually to ensure accurate wall detection. The region of interest was kept constant throughout each protocol to minimize artificial intrasubject variation. Baseline diameter was averaged over one minute during the initial resting period. Diameters were compiled into three-second average time bins from which peak diameter and time-to-peak diameter were identified. Flow-mediated dilation was calculated as the percent increase from baseline to the peak diameter bin during reactive hyperemia. Ultrasound analyses were performed by a single trained investigator. The laboratory assistant analyzing FMD was blinded to test identifiers, including group. 
Shear rate.-Velocity $(\mathrm{cm} / \mathrm{s})$ was obtained for each frame and compiled into 3 second average time bins. Shear rate was calculated for each bin as mean velocity/mean diameter. Shear rate AUC was calculated from cuff deflation to the time of peak dilation using the trapezoid rule 21,23 . Arterial blood pressure was obtained using a manual sphygmomanometer by the same technician at the end of each FMD testing session after the subject had been lying supine for at least 30 minutes.

Statistical analyses.-Two-tailed $t$-tests were used to compare baseline differences in all variables between groups. A value of $P<0.05$ was considered significant. Values in tables are reported as the mean \pm standard deviation and in graphs as mean \pm SEM. Pearson's product moment correlation was used to assess the relationship FMD to either testosterone or $\mathrm{Hb}$. Data were analyzed using SPSS Statistical Software (IBM, Armonk, New York)

\section{RESULTS}

By design, transgender subjects had higher $\left[\mathrm{T}_{\text {Total }}\right] \mathrm{S}$ and $\left[\mathrm{T}_{\text {free }}\right] \mathrm{S}$. Most other blood variables were similar between groups, including lipids and triglycerides, although $\mathrm{HbA}_{1 \mathrm{C}}$ was higher in the TGM (Table 1). Hemodynamic variables were also similar between groups and within normal ranges (Table 2).

\section{Effect of group on flow mediated vasodilation.}

The magnitude of vasodilatory responses was attenuated in the TGM (Table 2, Figure 1, $P=0.002$ ). This difference in vasodilatory response was independent of baseline diameter (Table 2, Figure 1, $P=0.707)$. Shear rate AUC was unaffected by group $(28,091 \pm 13,187$ vs. $18,330 \pm 2,476, P=0.075$, Table 2). Although there was some trend for greater shear rate AUC in the cisgender versus the transgender group, we found no correlation between shear rate AUC and percent FMD in either group $\left(\mathrm{r}^{2} 0.18, P=0.045\right.$, cisgender, $\mathrm{r}^{2} 0.17, \mathrm{P}<0.71$, transgender) so did not normalize percent FMD to the shear stress stimulus ${ }^{23}$. There was a significant linear correlation between $\left[\mathrm{T}_{\text {free }}\right] \mathrm{S}$ and FMD when the TGM and CGF groups were considered together $\left(\mathrm{r}^{2}=0.32, \mathrm{P}=0.002\right)$. However, within groups, this relationship was not significant. There was no significant linear correlation between $\mathrm{Hb}$ and FMD either within the groups or when the groups were considered together $\left(\mathrm{r}^{2}=0.0004, \mathrm{P}=0.99\right)$.

\section{DISCUSSION}

We demonstrated for the first time that physiological testosterone administration during HT was associated with impaired endothelial function in young TGM compared to CGF women. Our findings are consistent with earlier data showing endothelium mediated vasodilation is attenuated in lean, insulin-sensitive women with AE-PCOS with endogenous hyperandrogenism ${ }^{11}$. Importantly, the difference in endothelial function between TGM and CGF was found despite comparable levels of traditional cardiovascular risk factors including BMI, lipid levels and blood pressure, suggesting that other mechanisms such as inflammation or the direct effect of androgens may contribute to changes in endothelial function. There was a small but statistically significant difference in $\mathrm{HbA}_{1 \mathrm{C}}$ in the TGM (5.0 vs $4.7 \%, \mathrm{P}=0.048$ ), however the levels were well within the normal range and unlikely to have clinically relevant impact on vascular function. However, we cannot entirely exclude 
the possibility that subtle changes in cardiometabolic measurements may have a deleterious effect on endothelial function with long-term treatment. Earlier studies have shown adverse effects of testosterone on lipid levels and blood pressure ${ }^{17,24}$, raising concern for increased cardiovascular risk with chronic testosterone exposure. Therefore, attention to cardiometabolic risk factors should be integral to the care of TGM. Finally, because of experimental constraints, our laboratory tests were performed by different laboratories so we were unable to directly compare lipids and hormones between the two groups so these studies should be repeated with blood analysis performed using the same assays for both groups.

Endothelial dysfunction constitutes "the early pivotal event in atherosclerosis" 25 , because it precedes clinically detectable atherosclerotic plaques in the coronary arteries. Healthy endothelial function may be described as a balance of endothelial vasoconstrictor/vasodilator factors. A primary feature of normally functioning endothelium is the production of nitric oxide in response a number of different agonists (e.g. shear stress in FMD). Testosterone exposure is also associated with impaired agonist-triggered endothelial NO release in women ${ }^{3,4}$, and is therefore a major driver of endothelial dysfunction. Activation of the AR in women may result in impaired, agonist-triggered endothelial NO release and/or NO responsiveness. A recent study in our laboratory demonstrated impaired endothelin-1 (agonist) triggered vasodilation in lean, insulin sensitive women with AE-PCOS, indicating an independent effect of androgen on vascular pathology in these women with high testosterone exposure but no insulin resistance or obesity ${ }^{11}$. This same study indicated the endothelial dysfunction in AE-PCOS is mediated through an androgen effect on the NO pathway ${ }^{11}$. Earlier data in PCOS had demonstrated that inflammation and inflammatory factors including cytokines, oxidative stress and NF- $\kappa \mathrm{B}$ activation ${ }^{26}$ also contribute to the impaired NO release or responsiveness ${ }^{5,6}$. These data are consistent with our current findings that the impaired endothelial function in TGM is independent of obesity or blood lipids and likely associated with inflammatory factors associated with the testosterone exposure.

Testosterone is an acute vasodilator and in men may protect against endothelial dysfunction ${ }^{27}$. Androgen receptors are expressed in cells throughout the cardiovascular system, including endothelial cells ${ }^{28}$ and vascular smooth muscle cells (VSMCs) ${ }^{29}$, although the impact of testosterone administration on the cardiovascular system in men is varied $^{2,30-33}$. In contrast, androgens may induce detrimental outcomes on the cardiovascular system in women ${ }^{2-4}$. In general, the engagement of androgen and the androgen receptor results in impaired, agonist-triggered endothelial NO release in women, a likely cause of the sex differences in testosterone effects on endothelial function. A recent meta-analysis of androgen (DHT) treatment showed dyslipidemia at 3, 6 and 24 months of testosterone treatment in transmen ${ }^{17}$. While HT with testosterone also induced blood pressure increases, insulin resistance, and dyslipidemia ${ }^{17}$, cardiovascular morbidity or mortality was not yet apparent in these young transgender men ${ }^{24}$. No studies have yet followed transgender men into the aging process as cardiovascular disease risks accelerate, therefore the long-term impact on cardiovascular disease remains unknown. 
Earlier studies have shown $\mathrm{Hb}$ and Hct during testosterone treatment (in men) can increase iron and red blood cell formation ${ }^{34}$, and that $\mathrm{Hb}$ is inversely related to forearm endothelialdependent vasodilation ${ }^{35}$. However, in this study, while Hct was greater in the TGM versus the CGF, there was no relationship within either group to FMD or when we considered the groups as a whole. Further studies examining this specific relationship are required as our blood samples and FMD measures in TGM were not taken on the same day, and $\mathrm{Hb}$ and Hct are sensitive to hydration and posture, among other variables.

In women, $\left[\mathrm{T}_{\text {Total }}\right] \mathrm{S}$ is associated with greater risk of diabetes and related cardiovascular comorbidities ${ }^{37}$. In the present study, we noted small but significantly greater $\mathrm{HbA}_{1 \mathrm{C}}$ in the TGM (5.0 vs $4.7, P=0.048)$ in this young, healthy cohort. In this group we would expect the incidence of impaired glucose metabolism to be very low. The normal range for $\mathrm{HbA}_{1 \mathrm{C}}$ is $<5.7 \%$, prediabetes is defined as an $\mathrm{HbA}_{1 \mathrm{C}} 5.7-6.4 \%$, and diabetes is defined as an $\mathrm{HbA}_{1 \mathrm{C}} \geq$ $6.5 \%$. All subjects in both groups were in the normal range (4.0-5.6\%), suggesting while this was statically different, there is little physiological or clinical consequence.

\section{Conclusions}

Ours is the first study to examine the androgen effects on endothelial function in TGM. We demonstrated that the hyperandrogenic milieu in TGM is a primary factor associated with endothelial dysfunction, independent of lipids, blood pressure and BMI. Our present study supports earlier studies from our laboratory demonstrating that poor NO responsiveness is a key causative link in natal females exposed to chronic endogenous and/or high levels of exogenous androgens leading to endothelial dysfunction and ultimately cardiovascular disease. Future studies should address how changes in other hormones such as estrogen, or other substances, such as inflammatory cytokines, may impact changes in vascular function during HT. As described earlier, endothelial dysfunction in these TGM occurred independent of differences in lipids, BMI or blood pressure indicating a separate etiology. Understanding the mechanisms by which exogenous androgens mediate endothelial dysfunction in TGM may allow for early interventions to mitigate the potential long-term cardiovascular risk.

\section{Limitations:}

The blood analyses of the different groups were performed by different laboratories. This was necessary as our TGM subjects were recruited by their physicians (BG and PP), who had performed blood testing as part of their regular examinations. We did not wish to repeat unnecessary blood testing or invasive measures. A second limitation was that we did not collect the blood sample on the same day the FMD was performed. However. With regard to the testosterone our treatment was within standard parameters, and subjects received testosterone therapy at least once per week throughout the study. A third limitation was the cross-sectional nature of our study. Future studies will include TGM prior to and after having begun HT so we can study changes in cardiovascular function as they proceed through HT. Such longitudinal studies are needed to confirm these findings and enable us to better isolate the time course for these changes in endothelial function. These longitudinal studies will also allow us to test hypotheses relating to mechanisms involved in the testosterone effects on endothelial function in TGM. 


\section{ACKNOWLEDGMENTS}

We gratefully acknowledge the cooperation of the volunteer subjects.

Financial Support:

NSS and CAL were supported by NIH R01 \# HL135089 and internal funding from the John B. Pierce Laboratory.

\section{REFERENCES}

1. Flores A, H. J., Gates GJ, Brown TNT (2016) How Many Adults Identify as Transgender in the United States? The Williams Institute, Los Angeles.

2. Stanhewicz AE, Wenner MM \& Stachenfeld NS (2018) Sex differences in endothelial function important to vascular health and overall cardiovascular disease risk across the lifespan. Am J Physiol. Heart Circ Physiol 315, H1569-H1588. [PubMed: 30216121]

3. Liu PY, Death AK \& Handelsman DJ (2003) Androgens and cardiovascular disease. Endocr Rev 24, 313-340. [PubMed: 12788802]

4. Dixit KCS, Wu J, Smith LB, Hadoke PWF \& Wu FCW (2000) Androgens and Coronary Artery Disease In Endotext eds. De Groot LJ, Chrousos G, Dungan K, Feingold KR, Grossman A, Hershman JM, Koch C, Korbonits M, McLachlan R, New M, Purnell J, Rebar R, Singer F \& Vinik A, South Dartmouth (MA).

5. Yavuz Taslipinar M, Kilic N, Bayraktar N, Guler I, Gulcan Kurt Y, Goktas T, Taner MZ, Himmetoglu MO, Yaman H \& Taslipinar A (2014) Endothelial dysfunction and insulin resistance in young women with polycystic ovarian syndrome. Turk J Med Sci 44, 787-791. [PubMed: 25539546]

6. Krishna MB, Joseph A, Thomas PL, Dsilva B, Pillai SM \& Laloraya M (2017) Impaired arginine metabolism coupled to a defective redox conduit contributes to low plasma nitric oxide in polycystic ovary syndrome. Cellular Physiology and Biochemistry 43, 1880-1892. [PubMed: 29055959]

7. Paradisi G, Steinberg HO, Hempfling A, Cronin J, Hook G, Shepard MK \& Baron AD (2001) Polycystic ovary syndrome is associated with endothelial dysfunction. Circulation 103, 1410-1415. [PubMed: 11245645]

8. McCrohon JA, Jessup W, Handelsman DJ \& Celermajer DS (1999) Androgen exposure increases human monocyte adhesion to vascular endothelium and endothelial cell expression of vascular cell adhesion molecule-1. Circulation 99, 2317-2322. [PubMed: 10226099]

9. Gui J \& Wang R. h. (2017) Cardiovascular autonomic dysfunction in women with polycystic ovary syndrome: a systematic review and meta-analysis. Reproductive BioMedicine Online 35, 113-120. [PubMed: 28483340]

10. Ndefo UA, Eaton A \& Green MR (2013) Polycystic ovary syndrome: a review of treatment options with a focus on pharmacological approaches. P \& T : a peer-reviewed journal for formulary management 38, 336-355. [PubMed: 23946629]

11. Usselman CW, Yarovinsky TO, Steele FE, Leone CA, Taylor HS, Bender JR \& Stachenfeld NS (2019) Androgens drive microvascular endothelial dysfunction in women with polycystic ovary syndrome: role of the endothelin B receptor. The Journal of Physiology 597, 2853-2865. [PubMed: 30847930]

12. Quiros C, Patrascioiu I, Mora M, Aranda GB, Hanzu FA, Gomez-Gil E, Godas T \& Halperin I (2015) Effect of cross-sex hormone treatment on cardiovascular risk factors in transsexual individuals. Experience in a specialized unit in Catalonia. Endocrinol Nutr 62, 210-216. [PubMed: 25790747]

13. Wierckx K, Van Caenegem E, Schreiner T, Haraldsen I, Fisher AD, Toye K, Kaufman JM \& T'Sjoen G (2014) Cross-sex hormone therapy in trans persons is safe and effective at short-time follow-up: results from the European network for the investigation of gender incongruence. J Sex Med 11, 1999-2011. [PubMed: 24828032]

14. Emi Y, Adachi M, Sasaki A, Nakamura Y \& Nakatsuka M (2008) Increased arterial stiffness in female-to-male transsexuals treated with androgen. J Obstet Gynaecol Res 34, 890-897. [PubMed: 18834347] 
15. Elbers JM, Giltay EJ, Teerlink T, Scheffer PG, Asscheman H, Seidell JC \& Gooren LJ (2003) Effects of sex steroids on components of the insulin resistance syndrome in transsexual subjects. Clin Endocrinol (Oxf) 58, 562-571. [PubMed: 12699437]

16. Colizzi M, Costa R, Scaramuzzi F, Palumbo C, Tyropani M, Pace V, Quagliarella L, Brescia F, Natilla LC, Loverro G \& Todarello O (2015) Concomitant psychiatric problems and hormonal treatment induced metabolic syndrome in gender dysphoria individuals: a 2 year follow-up study. J Psychosom Res 78, 399-406. [PubMed: 25691225]

17. Maraka S, Singh Ospina N, Rodriguez-Gutierrez R, Davidge-Pitts CJ, Nippoldt TB, Prokop LJ \& Murad MH (2017) Sex Steroids and Cardiovascular Outcomes in Transgender Individuals: A Systematic Review and Meta-Analysis. J Clin Endocrinol Metab 102, 3914-3923. [PubMed: 28945852]

18. Hembree WC, Cohen-Kettenis PT, Gooren L, Hannema SE, Meyer WJ, Murad MH, Rosenthal SM, Safer JD, Tangpricha V \& T'Sjoen GG (2017) Endocrine Treatment of Gender-Dysphoric/ Gender-Incongruent Persons: An Endocrine Society Clinical Practice Guideline. J Clin Endocrinol Metab 102, 3869-3903. [PubMed: 28945902]

19. Pyke KE \& Jazuli F (2011) Impact of repeated increases in shear stress via reactive hyperemia and handgrip exercise: no evidence of systematic changes in brachial artery FMD. Am J Physiol. Heart Circ Physiol 300, H1078-1089. [PubMed: 21186268]

20. Pyke KE \& Tschakovsky ME (2005) The relationship between shear stress and flow-mediated dilatation: implications for the assessment of endothelial function. J Physiol 568, 357-369. [PubMed: 16051630]

21. Adler TE, Usselman CW, Takamata A \& Stachenfeld NS (2018) Blood pressure predicts endothelial function and the effects of ethinyl estradiol exposure in young women. Am J Physiol. Heart Circ Physiol y 315, H925-H933.

22. Martin SS, Blaha MJ, Elshazly MB, Toth PP, Kwiterovich PO, Blumenthal RS \& Jones SR (2013) Comparison of a Novel Method vs the Friedewald Equation for Estimating Low-Density Lipoprotein Cholesterol Levels From the Standard Lipid ProfileNovel Method vs Friedewald Equation for Estimating LDL-CNovel Method vs Friedewald Equation for Estimating LDL-C. JAMA 310, 2061-2068. [PubMed: 24240933]

23. Thijssen DH, Black MA, Pyke KE, Padilla J, Atkinson G, Harris RA, Parker B, Widlansky ME, Tschakovsky ME \& Green DJ (2011) Assessment of flow-mediated dilation in humans: a methodological and physiological guideline. Am J Physiol. Heart Circ Physiol 300, H2-12. [PubMed: 20952670]

24. Streed CG Jr., Harfouch O, Marvel F, Blumenthal RS, Martin SS \& Mukherjee M (2017) Cardiovascular Disease Among Transgender Adults Receiving Hormone Therapy: A Narrative Review. Ann Intern Med 167, 256-267. [PubMed: 28738421]

25. Lambert EA, Teede H, Sari CI, Jona E, Shorakae S, Woodington K, Hemmes R, Eikelis N, Straznicky NE, De Courten B, Dixon JB, Schlaich MP \& Lambert GW (2015) Sympathetic activation and endothelial dysfunction in polycystic ovary syndrome are not explained by either obesity or insulin resistance. Clin Endocrinol (Oxf)

26. Diamanti-Kandarakis E (2008) Polycystic ovarian syndrome: pathophysiology, molecular aspects and clinical implications. Expert Rev Mol Med 10, e3. [PubMed: 18230193]

27. Kelly DM \& Jones TH (2013) Testosterone: a vascular hormone in health and disease. J Endocrinol 217, R47-71. [PubMed: 23549841]

28. Torres-Estay V, Carreno DV, San Francisco IF, Sotomayor P, Godoy AS \& Smith GJ (2015) Androgen receptor in human endothelial cells. J Endocrinol 224, R131-137. [PubMed: 25563353]

29. Lopes RAM, Neves KB, Pestana CR, Queiroz AL, Zanotto CZ, Chignalia AZ, Valim YM, Silveira LR, Curti C \& Tostes RC (2014) Testosterone induces apoptosis in vascular smooth muscle cells via extrinsic apoptotic pathway with mitochondria-generated reactive oxygen species involvement. Am J Physiol. Heart Circ Physiol 306, H1485-H1494. [PubMed: 24658017]

30. Miner M, Canty DJ \& Shabsigh R (2008) Testosterone replacement therapy in hypogonadal men: assessing benefits, risks, and best practices. Postgrad Med 120, 130-153. [PubMed: 18824832] 
31. Basaria S, Harman S, Travison TG \& et al. (2015) Effects of testosterone administration for 3 years on subclinical atherosclerosis progression in older men with low or low-normal testosterone levels: A randomized clinical trial. JAMA 314, 570-581. [PubMed: 26262795]

32. Vigen R, O’Donnell CI, Barón AE \& et al. (2013) ASsociation of testosterone therapy with mortality, myocardial infarction, and stroke in men with low testosterone levels. JAMA 310, 18291836. [PubMed: 24193080]

33. Sokolnicki LA, Khosla S \& Charkoudian N (2007) Effects of testosterone and estradiol on cutaneous vasodilation during local warming in older men. Am J Physiol Endocrinol Metab 293, E1426-1429. [PubMed: 17895284]

34. Beggs LA, Yarrow JF, Conover CF, Meuleman JR, Beck DT, Morrow M, Zou B, Shuster JJ \& Borst SE (2014) Testosterone alters iron metabolism and stimulates red blood cell production independently of dihydrotestosterone. Am J Physiol Endocrinol Metab 307, E456-E461. [PubMed: 25074984]

35. Maio R, Sciacqua A, Bruni R, Pascale A, Carullo G, Scarpino PE, Addesi D, Spinelli I, Leone GG \& Perticone F (2011) Association between hemoglobin level and endothelial function in uncomplicated, untreated hypertensive patients. Clin J Am Soc Nephrol 6, 648-655. [PubMed: 21071519]

36. Goetz LG, Mamillapalli R, Sahin C, Majidi-Zolbin M, Ge G, Mani A \& Taylor HS (2017) Addition of Estradiol to Cross-Sex Testosterone Therapy Reduces Atherosclerosis Plaque Formation in Female ApoE-/- Mice. Endocrinology 159, 754-762.

37. Diamanti-Kandarakis E, Spina G, Kouli C \& Migdalis I (2001) Increased endothelial-1 levels in women with polycystic ovary syndrome and the beneficial effect of metformin therapy. J. Clin. Endocrinol. Metab 86, 4666-4673. [PubMed: 11600523] 

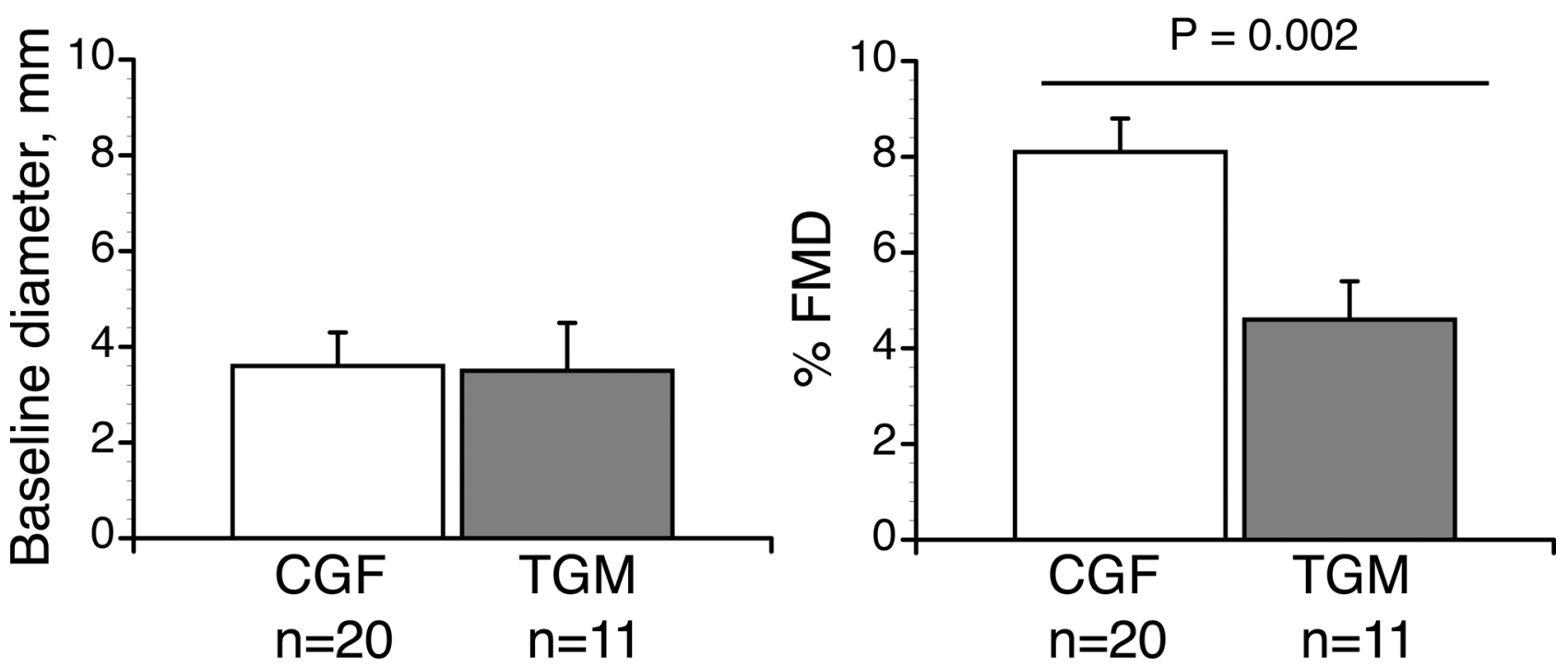

Figure 1.

Baseline dilation and flow mediated vasodilation (\%FMD) percent change. Data are presented as mean \pm SEM. Groups $n=11$ subjects in transgender men $($ TGM) group and $n=$ 20 cisgender female (CGF) group. Effect of group, $P=0.002$ for \%FMD with no difference in baseline diameter between groups. We used independent, two-tailed t-tests to test statistical significance in \%FMD and baseline dilation. 

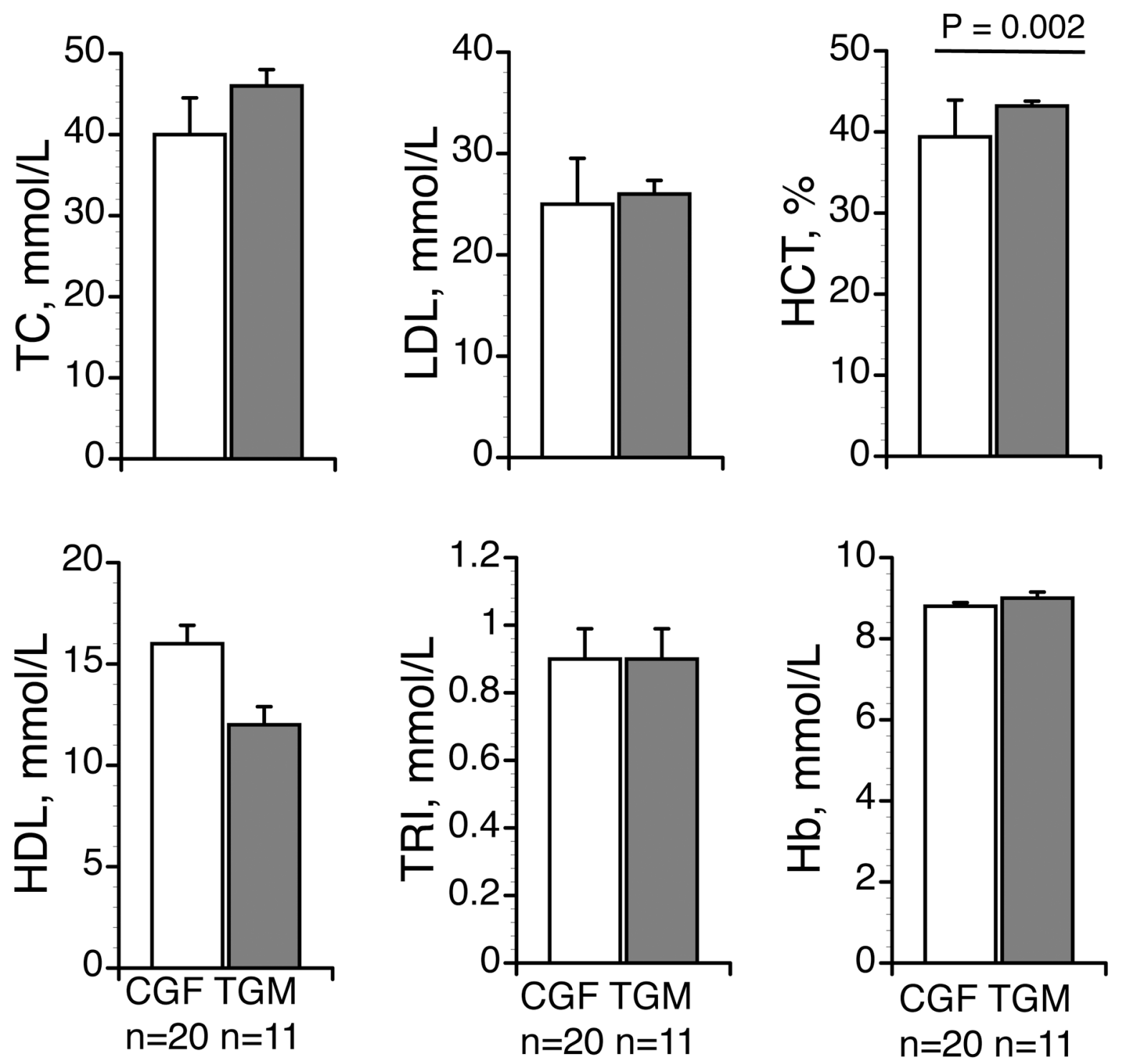

Figure 2.

Blood variables. Data are presented as mean \pm SEM. Groups $n=11$ subjects in transgender men (TGM) group and $n=20$ cisgender female (CGF) group. Total cholesterol (TC), low (LDL) and high (HDL) density lipoproteins, Triglycerides (TRI) hematocrit (Hct), Effect of group, $P=0.002$ for hemoglobin $(\mathrm{Hb})$. 
Table 1.

Data are presented as mean $\pm \mathrm{SD}$, independent, two-tailed, t-tests were used to test statistical significance. BMI, body mass index, low (LDL and high (HDL) density lipoproteins, hematocrit (Hct), Hemoglobin (Hb), $17 \beta$-estradiol (E2). *n=6 for transmen for E2 values. Based on clinical practice guidelines, E2 levels are no longer measured once an the E2 level is consistently below $50 \mathrm{pg} / \mathrm{ml}$, menses stop or the individual has had total abdominal hysterectomy with bilateral salpingo-oophorectomy (TAH/BSO). We removed one E2 outlier from the TGM group (668.1 pmol/L) as this was an inconsistent finding within this subject. We elected to keep this subject in the study because his testosterone was within range and FMD was also low. Significance was accepted at $P<0.05$ and indicated in boldface in the table.

\begin{tabular}{|c|c|c|c|}
\hline & Transgender Men & Cisgender Women & $P$ \\
\hline $\mathrm{n}$ & 10 & 20 & \\
\hline Age, $\mathrm{y}$ & $27 \pm 4$ & $28 \pm 5$ & 0.389 \\
\hline Race (Asian/Black/White/Hispanic) & $(2 / 1 / 6 / 1)$ & $71.1 \pm 14.0$ & NA \\
\hline Weight, $\mathrm{kg}$ & $66.8 \pm 10.1$ & $166.9 \pm 8.1$ & 0.386 \\
\hline Height, cm & $165.4 \pm 7.6$ & $26.0 \pm 5.1$ & 0.642 \\
\hline BMI, $\mathrm{kg} / \mathrm{m}^{2}$ & $24.4 \pm 14.9$ & $4.7 \pm 0.4$ & 0.392 \\
\hline HbA $1 \mathrm{C}, \%$ & $5.0 \pm 0.2$ & $46 \pm 9$ & $\mathbf{0 . 0 4 8}$ \\
\hline Total Cholesterol, mmol/L & $40 \pm 15$ & $25 \pm 6$ & 0.785 \\
\hline LDL, mmol/L & $26 \pm 6$ & $16 \pm 4$ & 0.820 \\
\hline HDL, $\mathrm{mmol} / \mathrm{L}$ & $12 \pm 5$ & $0.9 \pm 0.4$ & 0.146 \\
\hline Triglycerides, $\mathrm{mmol} / \mathrm{L}$ & $0.9 \pm 0.5$ & $39.9 \pm 2.9$ & 0.501 \\
\hline Hct, $\%$ & $43.2 \pm 1.9$ & $8.9 \pm 1.2$ & $\mathbf{0 . 0 0 2}$ \\
\hline Hb, mmol/L & $8.8 \pm 0.6$ & $222.4 \pm 126.6(\mathrm{n}=20)$ & 0.683 \\
\hline E2, pmol/L* & $167.7 \pm 62.4(\mathrm{n}=6)$ & $5 \pm 2$ Range, $2-8$ & $\mathbf{5 . 6 7 8}{ }^{\mathrm{e}-22}$ \\
\hline Total Testosterone, $\mathrm{nmol} / \mathrm{L}$ & $1763 \pm 270$ Range, $866-3813$ & $0.05 \pm 0.02$ range: $0.02-0.08$ & $\mathbf{6 . 1 0 6}{ }^{\mathbf{e}-11}$ \\
\hline Free Testosterone, $\mathrm{nmol} / \mathrm{L}$ & $0.30 \pm 0.13$ range: $0.15-0.78$ & & \\
\hline
\end{tabular}


Table 2.

Flow Mediated Vasodilation and hemodynamic variables.

Data are presented as mean $\pm \mathrm{SD}$, independent, two-tailed, t-tests were used to test statistical significance.

BMI, body mass index, SBP, DBP, and MAP, systolic, diastolic and mean arterial blood pressure. Groups: $\mathrm{n}=$ 20 in the cisgender group and $n=11$ subjects in the transgender group.

\begin{tabular}{|c|c|c|c|}
\hline & Transgender Men & Cisgender Women & $\boldsymbol{p}$ \\
\hline $\mathrm{n}$ & 11 & 20 & \\
\hline Baseline diameter, mm & $3.5 \pm 0.4$ & $3.6 \pm 1.0$ & 0.707 \\
\hline FMD, \% & $4.5 \pm 2.7$ & $8.1 \pm 2.9$ & $\mathbf{0 . 0 0 2}$ \\
\hline Shear rate, AUC & $28,089 \pm 13,187$ & $18,340 \pm 6,550$ & 0.075 \\
\hline SBP, mm Hg & $123 \pm 11$ & $117 \pm 10$ & 0.157 \\
\hline DBP, $\mathrm{mm} \mathrm{Hg}$ & $78 \pm 12$ & $73 \pm 10$ & 0.241 \\
\hline MAP, mm Hg & $93 \pm 10$ & $88 \pm 10$ & 0.186 \\
\hline
\end{tabular}

